\title{
Edge Preparation of CUTting ToOls AND IT IMPACT ON CUTTING ForCES DURING MILLING
}

\author{
Vladimír Šimna, František Jurina*, Tomáš Vopát, Marcel Kuruc
}
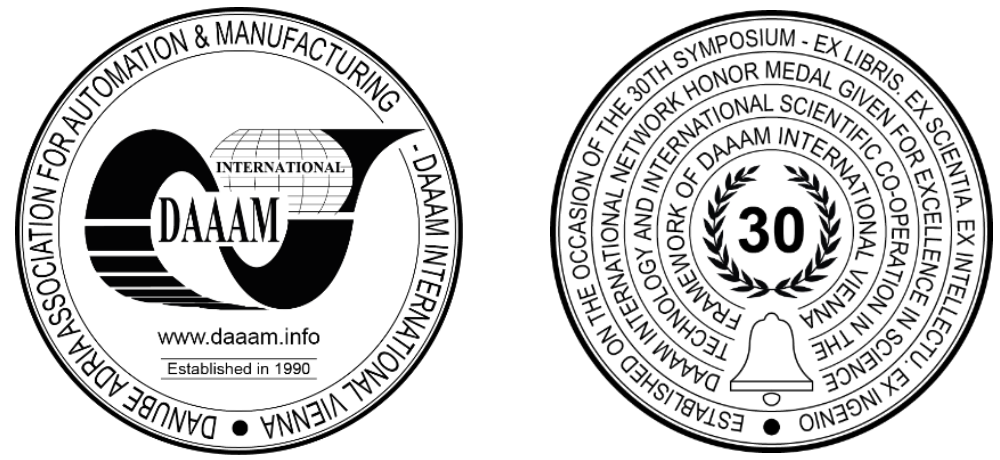

This Publication has to be referred as: Simna, V[ladimir]; Jurina, F[rantisek]; Vopat, T[omas] \& Kuruc, M[arcel] (2019). Edge Preparation of Cutting Tools and it Impact on Cutting Forces During Milling, Proceedings of the 30th DAAAM International Symposium, pp.0764-0769, B. Katalinic (Ed.), Published by DAAAM International, ISBN 9783-902734-22-8, ISSN 1726-9679, Vienna, Austria DOI: $10.2507 / 30$ th.daaam.proceedings.105

\begin{abstract}
The aim of this paper is to find out how the edge preparation of cutting tools affects cutting forces in milling. The theoretical analysis was focused on the cutting edge geometry, edge preparation and cutting forces. In the practical part of this paper is described the procedure of preparation and the process of the experiment in which was measured and watched the behavior of cutting forces on end mills with different cutting edge radius. Results from cutting force measurement are described and evaluated in the final part of this paper. These results were investigated in the process of machining of stainless austenitic steel (AISI 316L). The Kistler model 5070A dynamometer was used to measure the cutting forces. The results of the experiment showed that the cutting edge preparation has a significant influence on the cutting forces during milling.
\end{abstract}

Keywords: cutting edge preparation; cutting force; cutting edge radius

\section{Introduction}

During machining there are high local pressures between the tool and the workpiece, high temperatures, cutting forces, etc. The cutting temperature, which is generated during cutting process, exposes the cutting tool to extreme thermal conditions. Heat, which is also generated by chip formation and by the friction on the rake face during high speed cutting, is adverse effect. This adverse effect can influence the tool life. At both discontinuous and continuous cut the cutting forces act unstable that is caused by small and very hard elements in the workpiece microstructure. [1]

The theoretical analysis was focused on the issue of cutting edge microgeometry, discussing the classification and importance of cutting edge microgeometry and edge preparation methods. Publications in [2],[3] were focused on the optimum shape of cutting edge and surface of cutting tool that was prepared by various preparation methods. Denkena et al. [4] found that mill wear behavior depends on the design of the location and the undercut at the cutting edge. The cutting edge radius is very important factor in consideration of chip formation process especially in micro machining [5]. Authors in [6] confirmed that cutting forces are negatively affected by small feed rate near the cutting edge radius due to a disturbed chip formation. Ventura et al. [7] documented that asymmetric microgeometry increases tool life. The applicability of the prepared cutting inserts was demonstrated and the use of asymmetric microgeometries in hard turning 
proved to be adequate with respect to compressive residual stresses, though higher cutting forces were obtained. Vopát et al. [9] introduce a new method with interesting results. In publication for cutting edge preparation the plasma discharges in electrolyte was used.

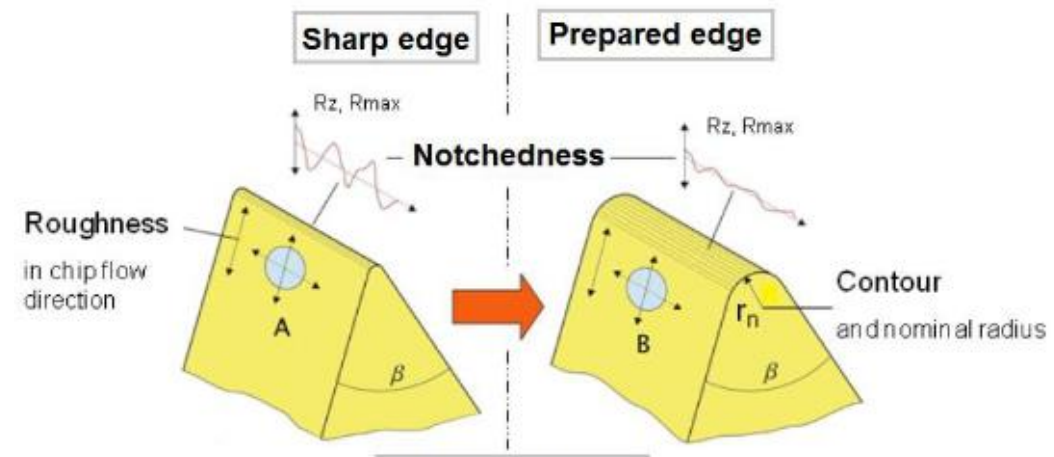

THE REAL TOOL
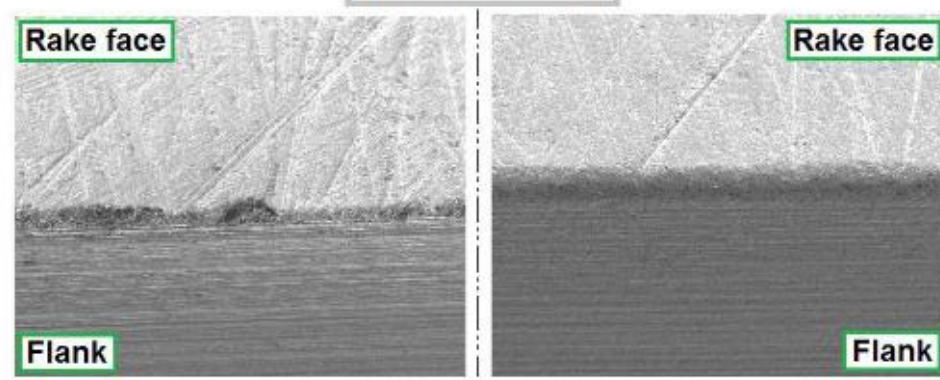

Fig. 1. Characterization of cutting edge preparation [8]

In the Fig. 1. the difference between sharp cutting edge and prepared edge is shown. The cutting edge preparation can influence: cutting forces/gyroscopic moment, cutting forces, tool wear-tool life, chip formation, quality of machined surface, accuracy of machining, adhesion of deposited thin layer, etc. [1].

The appropriate cutting edge geometry is often discussed in many research works. There is a many different methods for cutting edge preparation, such as drag-finishing, electro-erosion, microblasting or laser ablation. [10], [11], [12], [13], [14].

Hronek et al [15] investigate the influence of Cutting Edge Radius on Force Load when Milling Inconel 718.

An ideal cutting tool has the highest mechanical stability, the lowest wear and therefore the maximum tool life within a wide range of process parameters. The design of the cutting edge microgeometry influences the cutting tool-workpiece interface in the shear zone. Consequently the magnitude and distribution of the thermal and mechanical load on the wedge are affected by these changes. These influence in turn the wear behavior of the cutting tool. Adapting the appropriate design of the cutting edge microgeometry in combination with a high performance coating leads to significantly higher tool life values. [16].

Authors in [17] proved that the tool life of cemented carbide drills increases when cutting edge radius is larger.

\section{Materials and methods}

The aim of the research was to prove the effect of cutting edge microgeometry on the cutting forces during milling. It has been investigated how the different radius of the cutting edge curvature affects the cutting forces when milling difficult to cut stainless austenitic steel (AISI 316L). Three milling cutters with cutting edge radii $r_{n 1}=5 \mu \mathrm{m}, r_{n 2}=15 \mu \mathrm{m}$ and $r_{n}$ $=30 \mu \mathrm{m}$ were investigated. Face milling was chosen as milling method. The cutting conditions were set up for finishing operation. Cutting forces were measured using a Kistler dynamometer. From the dynamometer clamped in the machine, the values were transferred to a computer via a cable where they were recorded and evaluated using Dynoware software from Kistler. From the records of the cutting forces, we investigated changes in the size and characteristics of the cutting force at one rotation of the milling cutter at different times and at different wear due to different radius of cutting edge radius. Summary of results and values is written and evaluated in the last chapter of paper.

\subsection{Machine tool and cutting tool}

The experiment was performed on a DMU 85 MonoBLOCK 5-axis machine tool by DMG Mori. As testing tools for this experiment, milling cutters with geometry designed for machining austenitic stainless steel were designed and manufactured. The milling cutters were made on a Reinecker WZS60 grinding machine. The milling tools diameter was set to $10 \mathrm{~mm}$. Milling tool geometry was measured on a 5-axis CNC-controlled Zoller Genius 3s cutting tool inspection 
machine. The milling tool was made from CTS 20D semi-finished material from Ceratizit. CTS is a sintered carbide having an average grain size of $7 \mu \mathrm{m}$ which ranks in this group of submicroscopic sintered carbides.

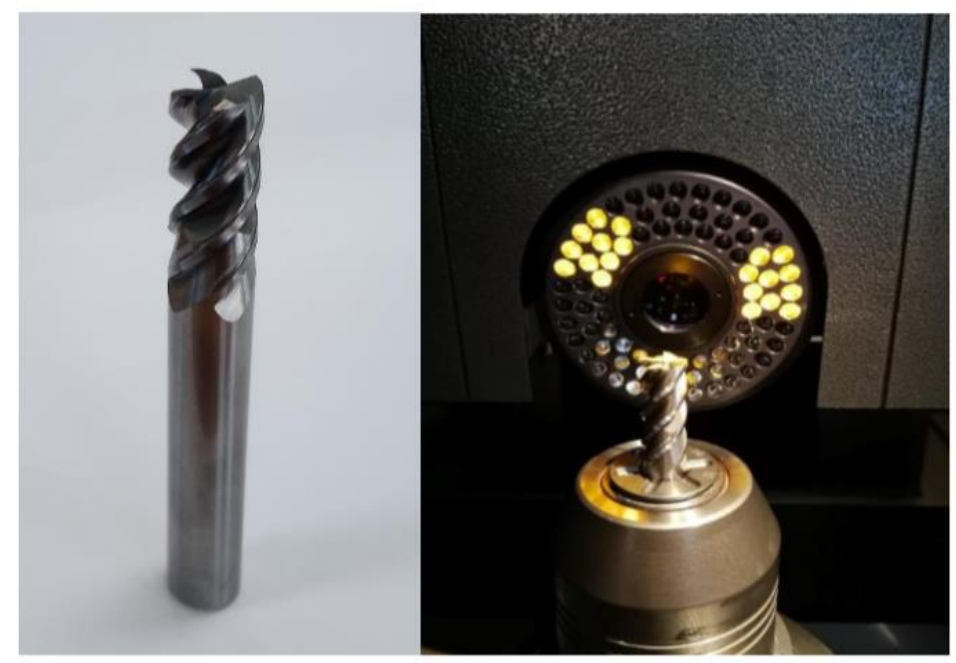

Fig. 2. Milling tool used in experiment

The cutting edge was subsequently prepared. The cutting edge preparation was performed on OTEC DF-3. SIX 70/16 granulate from OTEC was used as medium for cutting edge preparation. This medium is used for cutting edges preparation of carbide and HSS tools. For this experiment, the cutting edge radii $r_{n 1}=15 \mu \mathrm{m}$ and $\mathrm{rn} 2=30 \mu \mathrm{m}$ were set.

\subsection{Experiment conditions}

The cutting condition, which were used in experiment is shown in the Table 1 . The cutting speed was set using the Tylor formula for set optimum cutting speed for tool life 30 minutes.

\begin{tabular}{|c|c|}
\hline Cutting speed $\mathrm{v}_{\mathrm{c}}$ & $160 \mathrm{~m} \cdot \mathrm{min}^{-1}$ \\
\hline Axial depth of cut $-\mathrm{a}_{\mathrm{p}}$ & $0,5 \mathrm{~mm}$ \\
\hline Radial depth of cut $-\mathrm{a}_{\mathrm{e}}$ & $9 \mathrm{~mm}$ \\
\hline Revolution $-\mathrm{n}$ & $5111 \mathrm{~min}^{-1}$ \\
\hline Feed rate $\mathrm{f}$ & $400 \mathrm{~mm} \cdot \mathrm{min}^{-1}$ \\
\hline
\end{tabular}

Table 1. Cutting conditions used in experiment

The Kistler model 5070A dynamometer was used to measure the cutting forces. The dynamometer was clamped on a 5-axis machine tool. It was connected by a cable that transmitted information to a computer.

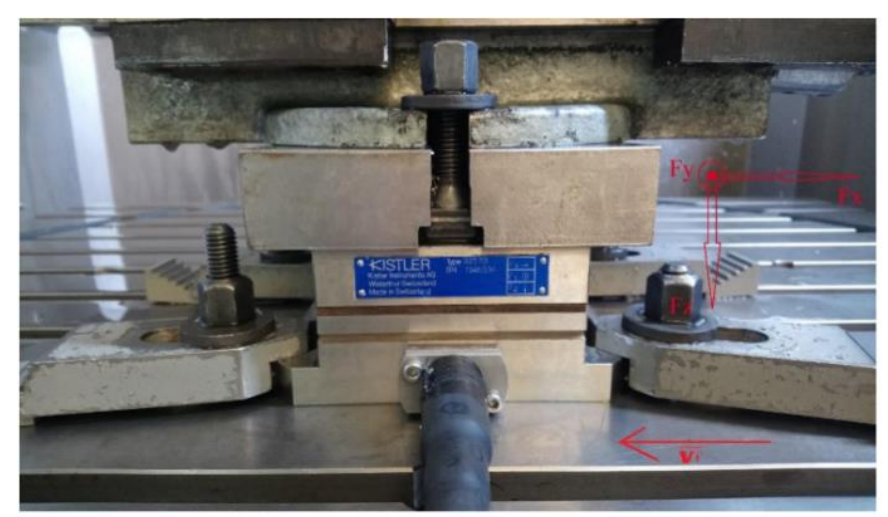

Fig. 3. Kistler dynamometer used in the experiment

Cutting force data were recorded and further evaluated using Dynoware software from Kistler. 


\section{Results and discussion}

\subsection{Cutting forces measurement in the $\mathrm{x}$-axis direction}

The cutting forces in the $\mathrm{F}_{\mathrm{x}}$ and $\mathrm{F}_{\mathrm{y}}$ axes were evaluated. Size of cutting forces and their behavior during one revolution of the milling cutter were evaluated.

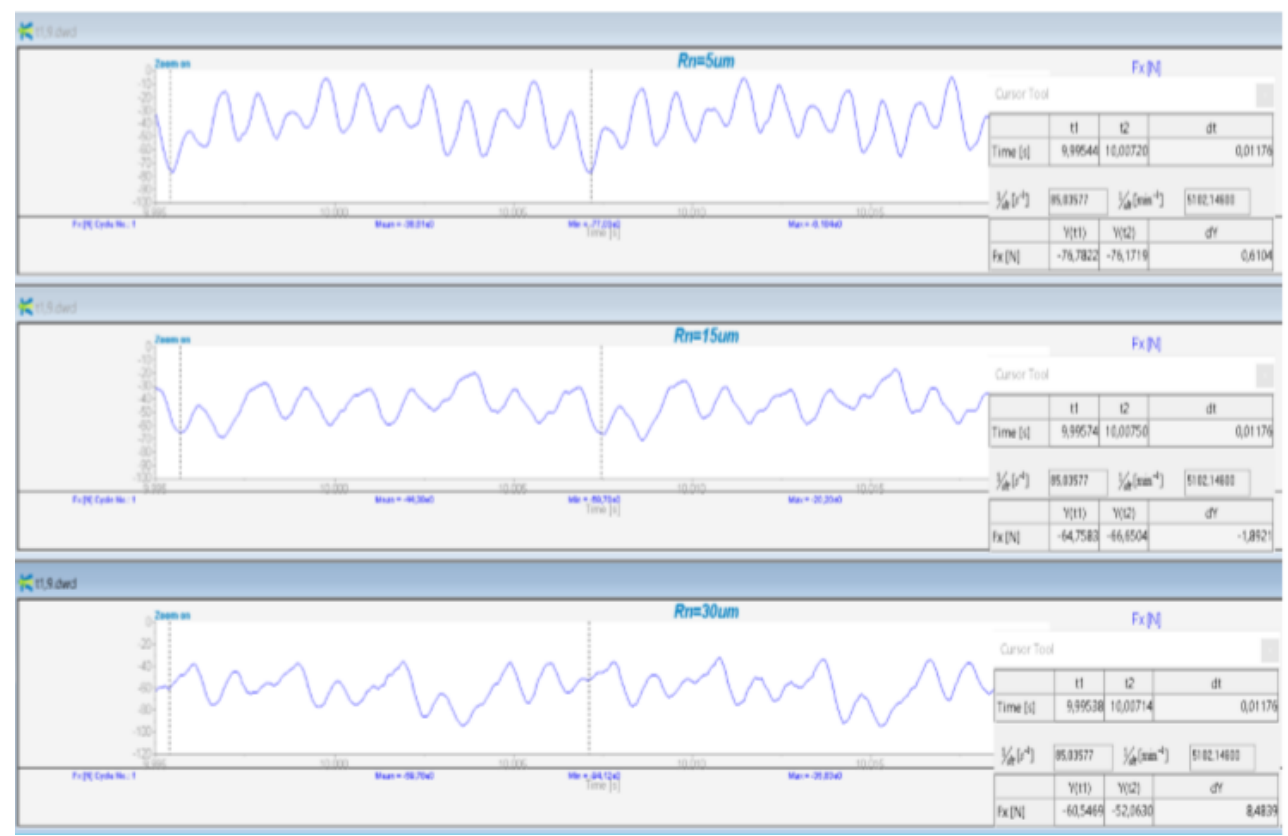

Fig. 4. Cutting forces for different cutting edge radius (From the top: $r_{n 1}=5, r_{n 2}=15, r_{n 3}=30$ )

From the values obtained and the graphical dependence (Fig. 5) of the cutting force component $F_{x}$, we can see that the difference in the size of the cutting force component $F_{x}$ is greatest at the beginning and at the end of the milling operation.

\section{Time [min]}

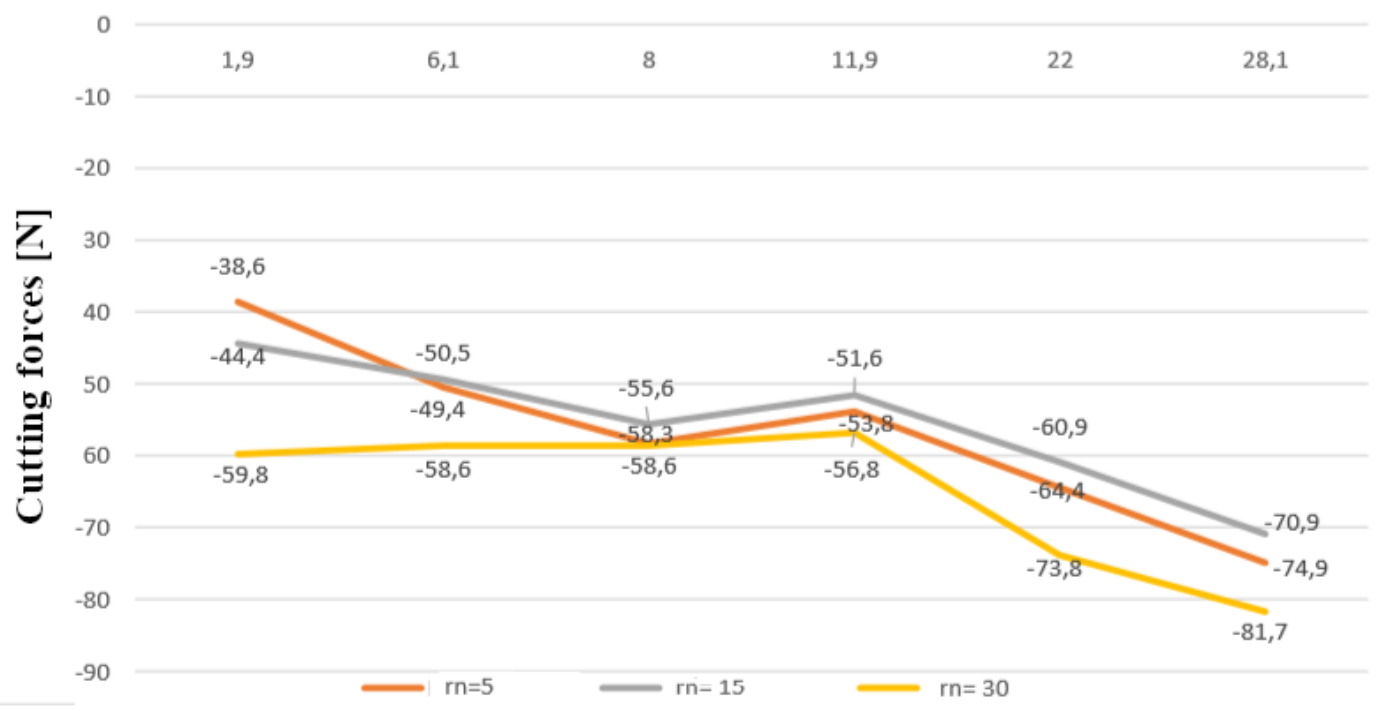

Fig. 5. Average value of the cutting force $\left(\mathrm{F}_{\mathrm{x}}\right)$ during 1revolution

From the theoretical analysis it is known that the preparation of the cutting edge helps to reduce the first part of the tool wear curve. This dependence has also been demonstrated for the measured values of the cutting force component $\mathrm{F}_{\mathrm{x}}$. For tool 1 with $r_{n}=5 \mu \mathrm{m}$, the force component size was smallest $(-38.6 \mathrm{~N})$, for milling cutter 2 with $\mathrm{r}_{\mathrm{n}}=15 \mu \mathrm{m}$ the cutting force component value was greater $(-44.4 \mathrm{~N})$ and for milling cutter $3 \mathrm{~s}_{\mathrm{n}}=30 \mu \mathrm{m}$ largest $(-59.8 \mathrm{~N})$. 
This implies that for a tool that has not been worn, the values of the cutting force component $F_{x}$ among the tested milling cutters are the smallest for a cutter with the smallest radius $r_{n}=5 \mu \mathrm{m}$. However, the values of the cutting force component Fx were approximately the same in the steady-state wear zone, from which we assume that after passing into the steady-state wear zone, the size of the cutting force components directly proportional to the wear.

\subsection{Cutting forces measurement in the y-axis direction}

The same procedure for evaluating the measurement results was chosen for the cutting force component $F_{y}$.

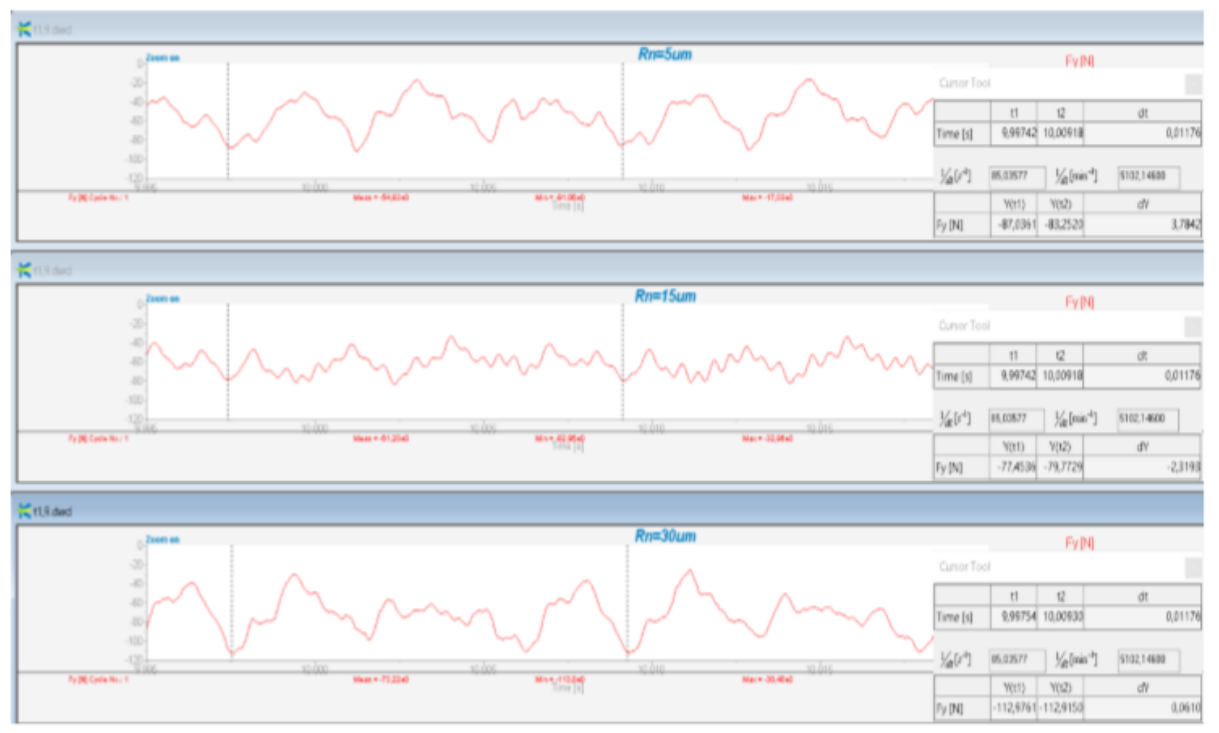

Fig. 6. Cutting forces for different cutting edge radius (From the top: $r_{n 1}=5, r_{n 2}=15, r_{n 3}=30$ )

From the values obtained and the graphical dependence (Fig. 7) of the cutting force component $F_{y}$.

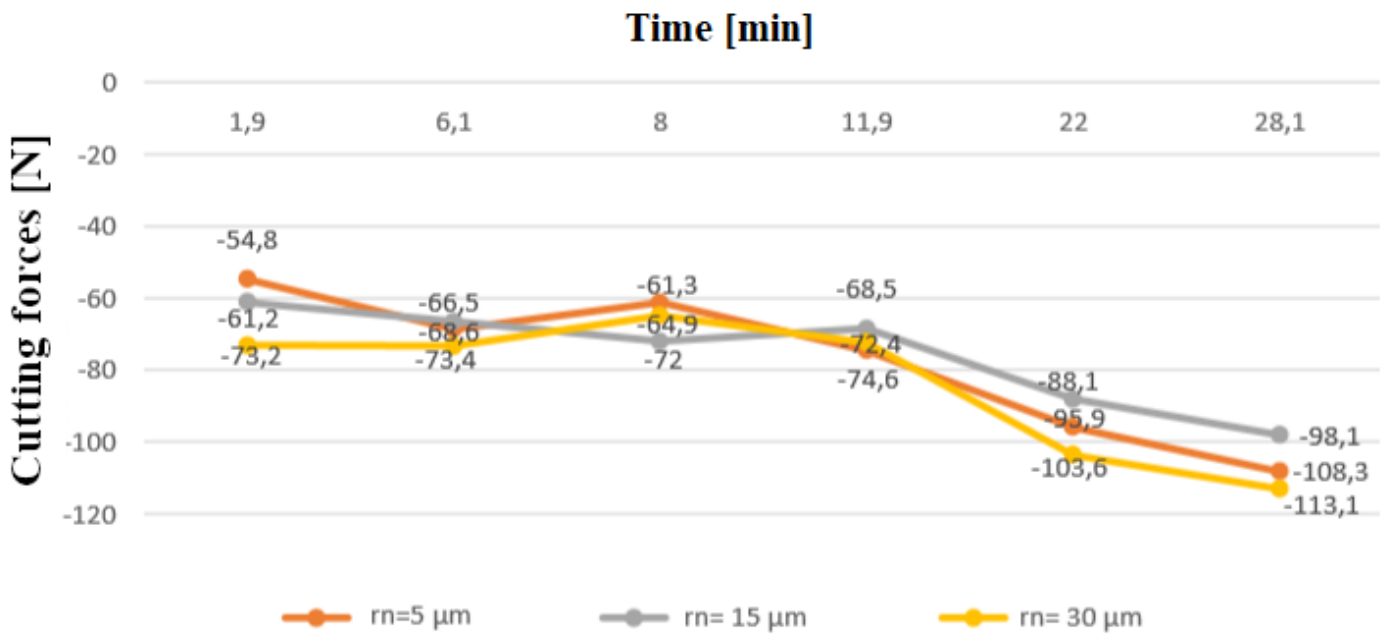

Fig. 7. Average value of the cutting force $\left(\mathrm{F}_{\mathrm{y}}\right)$ during 1 revolution

From the obtained values and graphical dependence of the cutting force component $\mathrm{F}_{\mathrm{y}}$ we can see that the behavior of the values of the cutting force component $F_{y}$ has a similar character as the behavior of the cutting force component $F_{x}$.

For non-prepared milling tool 1 with $r_{n}=5 \mu \mathrm{m}$, the force component size was the smallest $(-54.8 \mathrm{~N})$, for milling tool $2 r_{n}=15 \mu \mathrm{m}$, the cutting force component was greater $(-61.2 \mathrm{~N})$ and for milling tool $3 \mathrm{~s}_{\mathrm{n}}=30 \mu \mathrm{m}$ largest $(-73.2 \mathrm{~N})$. This means that with the milling tool which was not worn out, the values of the cutting force component $\mathrm{F}_{\mathrm{y}}$ among the tested milling cutters are the lowest for the non-prepared milling tool with the smallest cutting radius $r_{n}=5 \mu \mathrm{m}$.

\section{Conclusion}

The aim of this experiment was to theoretically discuss the issue of cutting edge cutting tools and investigate how the modified microgeometry of the cutting edge of the cutting tool affects the cutting forces during milling. The cutting forces 
in the milling of austenitic stainless steel AISI 316L were evaluated. During the evaluation, we focused on the effect of cutting forces in the $F_{x}$ and $F_{y}$ axis. From the obtained values we have clearly found that the cutting edge preparation affects the size of the cutting forces and their behavior during milling.

The obtained results has the significant role in the future research. In the future research, authors are going to focus on investigation of issue of cutting edge microgeometry during the machining the difficult-to-materials material such as Inconel superalloy. Authors are also going to determine the influence of edge preparation on the tool life of cemented carbide turning inserts and cemented carbide milling cutters.

\section{Acknowledgments}

This work was supported by the Scientific Grant Agency of the Slovak Republic under the grant no. 1/0097/17 and the Slovak Research and Development Agency of the Slovak Republic under the Contract no. APVV-16-0057. Authors are also grateful to Michal Durina, who assisted during the experiment.

\section{References}

[1] Fulemova J., Janda Z. (2014). Influence of the Cutting Edge Radius and the Cutting Edge Preparation on Tool Life and Cutting Forces at Inserts with Wiper Geometry, Procedia Engineering, 24th DAAAM International Symposium on Intelligent Manufacturing and Automation; Vol. 69, 565 - 573. https://doi.org/10.1016/j.proeng.2014.03.027

[2] Bouzakis K.D., Bouzakis E., Kombogiannis S., Makrimallakis S., Skordaris G., Michailidis N., et al. (2014) Effect of cutting edge preparation of coated tools on their performance in milling various materials. CIRP Journal of Manufacturing Science and Technology; Vol. 7, 264-73. https://doi.org/10.1016/J.CIRPJ.2014.05.003.

[3] Uhlmann E., Oberschmidt D., Löwenstein A., Kuche Y. (2016) Influence of cutting edge preparation on the performance of Micro milling tools. Procedia CIRP; Vol 46, $214-217$. https://doi.org/10.1016/J.PROCIR.2016.03.204.

[4] Denkena B., Köhler J., Bergmann B. (2015) Development of cutting edge geometries for hard milling operations. CIRP Journal of Manufacturing Science and Technology; Vol. 8, 43-52. https://doi.org/10. 1016/J.CIRPJ.2014.10.002.

[5] Teng X., Huo D., Chen W., Wong E., Zheng L., Shyha I. (2018) Finite element modelling on cutting mechanism of nano $\mathrm{Mg} / \mathrm{SiC}$ metal matrix composites considering cutting edge radius. Journal of Manufacturing Processes; Vol. 32, 116-26. https://doi.org/10.1016/J. JMAPRO.2018.02.006.

[6] Denkena B., Vehmeyer J., Niederwestberg D., Maßß P. (2014) Identification of the specific cutting force for geometrically defined cutting edges and varying cutting conditions. International Journal of Machine Tools and Manufacture; Vol. 82-83, 42-49. https://doi.org/10.1016/J. IJMACHTOOLS.2014.03.009

[7] Ventura C.E.H., Köhler J., Denkena B. (2013) Cutting edge preparation of PCBN inserts by means of grinding and its application in hard turning. CIRP Journal of Manufacturing Science and Technology; Vol.6, $246-253$. https://doi.org/10.1016/J.CIRPJ.2013.07.005.

[8] Rodríguez C.J.C. (2009) Cutting edge preparation of precision cutting tools by applying micro-abrasive jet machining and brushing, Mesogeometry of the cutting edge, ISBN 978-3-89958-713-5.

[9] Vopát T., Podhorský Š., Sahul M., Haršáni M. (2019) Cutting edge preparation of cutting tools using plasma discharges in electrolyte, Journal of Manufacturing Processes; Vol. 46, $234-240$. https://doi.org/10.1016/j.jmapro.2019.08.033.

[10] Biermann, D., Terwey, I., (2008) Cutting edge preparation to improve drilling tools for HPC processes, CIRP Journal of Manufacturing Science and Technology; Vol. 1/2: 76-80. https://doi.org/10.1016/j.cirpj.2008.09.002

[11] Denkena, B., de León-García, L., Bassett, E., (2008), Preparation of designed cutting edge microgeometries by simultaneous 5-axes brushing, Proceedings of the 3rd International Conference on Manufacturing Engineering (ICMEN) and EUREKA Brokerage Event, Kallithea of Chalkidiki (Greece); Vol. 2, $117-123$. https://doi.org/10.1007/BF03224185

[12] Reichmann S., (2011) "Komplette Oberfla“chenbehandlung durch magnetfinish", Schleifen + Polieren, Themenspecial Lappen und Honen, vol. 3: pp. 76-78.

[13] Aurich, J.C., Zimmermannand, M., Leitz, L., (2010) The Preparation of Cutting Edges Using a Marking Laser, Production Engineering, Vol. 5/1: 17-24. https://doi.org/10.1007/s11740-010-0275-9

[14] Yussefian, N., Koshy, P., Buchholz, S., Klocke, F., (2010) Electro-Erosion Edge Honing of Cutting Tools, CIRP Annals - Manufacturing Technology, Vol. 59/1, 215-218. https://doi.org/10.1016/j.cirp.2010.03.009

[15] Hronek, O., Zetek, M., Bakša, T., The Influence of Cutting Edge Radius on Force Load when Milling Inconel 718. 2018, 29th daaam proceedings. 119.

[16] E. Bassett, J. Köhler, B. Denkena, (2012) On the honed cutting edge and its side effects during orthogonal turning operations of AISI1045 with coated WC-Co inserts, CIRP Journal of Manufacturing Science and Technology, Vol. 5: 108-126. https://doi.org/10.1016/j.cirpj.2012.03.004 .

[17] Vopat T., Kuruc M., Šimna V. et al. The Influence of Cutting Edge Radius Size on the Tool Life of Cemented Carbide Drills, 2018, 29th daaam.proceedings . 